\title{
LITERACIA CIENTÍFICA: A IMPORTÂNCIA DA FORMAÇÃO DE COMPETÊNCIAS PARA A POPULARIZAÇÃo E PERCEPÇÃo PÚBLICA DE CT\&I
}

\section{Scientific literacy: the Importance of Competence Formation for the Popularization and Public Perception of ST\&I}

\author{
Cristiane Roque de Almeida ${ }^{1}$ \\ Emerson Adriano Guarda ${ }^{2}$ \\ Suyene Monteiro da Rocha ${ }^{3}$
}

\begin{abstract}
Resumo: Neste trabalho, tomamos a formação científica como objeto de estudo e questionamos como ela está contemplada no Plano Nacional de Educação - 2014-2024. O objetivo deste artigo é abordar a importância desse tipo de formação como estratégia, no ambiente escolar, para a aquisição da literacia científica, contribuindo para a popularização e melhoria da percepção pública da ciência, da tecnologia e da inovação. Trata-se de uma pesquisa qualitativa, bibliográfica, documental e analítico-descritiva, a qual utiliza-se da técnica de análise de conteúdo. Por meio de uma dimensão quantitativa complementar, é possível relacionar os dados indicadores da qualidade da educação nacional e da percepção pública de ciência e tecnologia no país com competências no domínio da literacia científica. Ainda mais, mostra-nos que o país precisa de uma revisão em sua política nacional de educação, considerando que os resultados dos indicadores revelam o não atingimento das metas estabelecidas. A formação científica deve ser considerada, ao longo de todo o percurso educativo, como uma valiosa ferramenta em prol de uma cidadania crítica e participativa na sociedade do conhecimento, importante processo de preparação para a literacia científica.
\end{abstract}

Palavras-chave: Consciência científica. Educação científica na Educação Básica. Literacia.

\begin{abstract}
In this research paper, we consider scientific training as an object of study and question how it is included in the National Education Plan (2014-2024). The aim of this article
\end{abstract}

\footnotetext{
${ }^{1}$ Doutoranda no Programa de Pós-graduação em Biodiversidade e Biotecnologia da Rede Bionorte da Amazônia Legal/Polo Tocantins - PPG-BIONORTE/UFT. Mestre em Sociologia pela Universidade Federal de Goiás - UFG. Professora Adjunta no Curso de Direito da UFT. E-mail: crisroque@ uft.edu.br. ORCID: https://orcid.org/00000003-2149-3855

${ }^{2}$ Doutor em Química Orgânica - UFSM. Professor associado no Programa de Pós-graduação em Biodiversidade e Biotecnologia da Rede Bionorte da Amazônia Legal/Polo Tocantins - PPG-BIONORTE/UFT e do Curso de Engenharia Ambiental da Universidade Federal do Tocantins. Coordenador do Laboratório de Pesquisa em Química Ambiental - LAPEQ/UFT. E-mail: emersonprof@ uft.edu.br. ORCID: https://orcid.org/0000-0003-02273881

3 Doutora em Biodiversidade e Biotecnologia - BIONORTE/UFAM. Mestre em Ciências do Ambiente - UFT. Professora Adjunta no curso de Direito da Universidade Federal do Tocantins. Coordenadora do grupo de pesquisa CNPq: Políticas Públicas Ambientais e Sustentabilidade. E-mail: suyenerocha@uft.edu.br. ORCID: https://orcid.org/0000-0001-6818-2013
} 
is to address the importance of this type of training as a strategy, in the school environment, for the acquisition of scientific literacy, contributing to the popularization and improvement of the public perception of science, technology and innovation. It is a qualitative, bibliographical, documentary and analytical - descriptive research, which uses the technique of content analysis. Through a complementary quantitative dimension, it is possible to relate the data indicating the quality of national education and the public perception of science and technology in the country to competences in the field of scientific literacy. Even more, it shows us that the country needs a review of its national education policy, considering that the indicators reveal the nonachievement of the established goals. Scientific training must be considered, throughout the educational pathway, as a valuable tool in favor of critical and active citizenship in the knowledge society, an important process of construction for scientific literacy.

Keywords: Scientific awareness. Science education in Basic Education. Literacy

\section{Introdução}

A atualidade requer ênfase na educação para a ciência e tecnologia, pois conquistas científicas históricas são questionadas, mesmo contra todas as evidências, pondo em questão as competências humanas para lidar com esse tipo de conhecimento, inclusive com repercussões para as tomadas de decisões com implicações coletivas. Nesse sentido, temos como pressuposto que o desenvolvimento da consciência científica precisa ser iniciado desde os primeiros anos de escolarização, e questionamos como a formação científica está contemplada no Plano Nacional de Educação - PNE (2014-2024) (BRASIL, 2014). Neste estudo, objetivamos abordar a relação dessa modalidade formativa, como estratégia no ambiente escolar, com a aquisição da literacia científica, bem como apontar a sua importância para a popularização e melhoria da percepção pública de ciência, tecnologia e inovação - CT\&I.

Como processo metodológico, realizamos análise qualitativa e documental do Plano Nacional de Educação - PNE (2014-2024), anexo à Lei n. 13.005, de 25 de junho de 2014. Orientamo-nos por uma perspectiva descritiva e explicativa, utilizando a técnica da análise de conteúdo de Bardin (1977), com três fases de abordagem do material analisado: por meio da pré-análise, buscamos as características principais do documento; posteriormente, fizemos a exploração do material, destacando os trechos diretamente relacionados ao tema em estudo; e, por fim, o tratamento dos dados, através das inferências, interpretações e atribuições de significados relativos aos contextos de análise.

Além do exposto, uma dimensão quantitativa complementar também está presente neste texto, com o uso de dados secundários que compõem o marco situacional da Educação Básica no Brasil, por meio dos Anuários Brasileiros da Educação Básica de 2019 e 2020, e da pesquisa 'Percepção Pública da Ciência e da Tecnologia no Brasil - 2019', realizada pelo Ministério da Ciência, Tecnologia, Informação e Comunicação - MCTIC, em parceria com o Centro de Gestão e Estudos Estratégicos - CGEE, com a colaboração do Instituto Nacional de Ciência e Tecnologia - Comunicação Pública da Ciência e Tecnologia (INCT-CPCT) e o apoio da Sociedade Brasileira para o Progresso da Ciência - SBPC.

O desenvolvimento deste artigo está estruturado em três partes. Inicialmente, diferenciamos os conceitos de alfabetização científica, letramento científico e literacia científica para, na sequência, abordarmos a formação científica na Educação Básica e sua relação com a literacia científica, como uma oportunidade na sociedade do conhecimento. Nesse momento, apresentamos os resultados da análise do PNE e dos dados do marco situacional da educação no Brasil. Por fim, trazemos os dados da pesquisa 'Percepção Pública 
da Ciência e Tecnologia no Brasil - 2019', enfatizando a importância da elevação da qualidade da educação em geral, e da educação científica em particular, para a popularização e valorização da ciência e a melhoria da percepção pública de ciência e tecnologia - C\&T, no Brasil, como indicadores de literacia científica.

\section{0 desenvolvimento da consciência científica}

Os conceitos de alfabetização científica e letramento científico são muito difundidos em pesquisas sobre a didática do ensino de ciências na Educação Básica, referindo-se às discussões sobre a educação científica e seus objetivos (MURI, 2017; SASSERON; CARVALHO, 2011; SANTOS, 2007; MAMEDE; ZIMMERMANN, 2005). Apesar de relacionados e indissociáveis, os dois conceitos se referem a processos que guardam, em sua gênese, diferenças importantes (SANTOS, 2007; MAMEDE; ZIMMERMANN, 2005).

Para Mamede e Zimmermann (2005), a alfabetização refere-se às habilidades e conhecimentos constitutivos de leitura e escrita, em um plano individual, e o letramento às práticas efetivas de leitura e escrita no plano social, de modo que "[...] uma pessoa letrada não é somente aquela que é capaz de decodificar a linguagem escrita, mas aquela que efetivamente faz uso desta tecnologia na vida social de uma maneira mais ampla" (MAMEDE; ZIMMERMANN, 2005, p. 1). As autoras consideram que, após sua gênese, o conceito de letramento foi se expandindo para outras esferas e, especificamente sobre o ensino de ciências, apontam que, muitas vezes, os dois conceitos são utilizados indiscriminadamente, "[...] referindo-se à importância de preparar o indivíduo para a vida em uma sociedade científica e tecnológica, na qual o conhecimento assume um papel essencial, dentro de uma perspectiva crítica da ciência e da tecnologia." (MAMEDE; ZIMMERMANN, 2005, p. 2).

É o que observamos em Chassot (2003), para quem o conceito de alfabetização científica, como uma possibilidade para a inclusão social, é apresentado de forma ampla, a partir de um conjunto de conhecimentos que, em qualquer nível de ensino, permite que os sujeitos sociais façam uma leitura do mundo em que vivem, tomem decisões e percebam tanto as utilidades da ciência quanto suas limitações e consequências negativas, em caso de uso indiscriminado. Para o autor, "[...] seria desejável que os alfabetizados cientificamente não apenas tivessem facilitada a leitura do mundo em que vivem, mas entendessem as necessidades de transformá-lo - e, preferencialmente, transformá-lo em algo melhor" (CHASSOT, 2003, p. 94).

O conceito de alfabetização científica em Chassot (2003) se aproxima do conceito de letramento científico utilizado no Programa Internacional de Avaliação de Estudantes - PISA ${ }^{4}$, o qual define letramento científico como resposta à seguinte pergunta: "O que é importante para os jovens saberem, valorizarem e serem capazes de fazer em situações que envolvem Ciência e Tecnologia?" (MURI, 2017, p. 37 cf. OCDE, 2016). Desse modo, o conceito de letramento é muito mais amplo do que a noção histórica de alfabetização, por ser sua aquisição algo que ocorre ao longo da vida em todas as situações de aprendizagem e em todos os espaços sociais (MURI, 2017). São domínios diferentes da educação científica que, mais do que uma discussão semântica, evocam "[...] processos escolares que busquem formas de contextualização do conhecimento científico em que os alunos o incorporem como um bem cultural que seja mobilizado em sua prática social." (SANTOS, 2007, p. 487). Nesse sentido, reivindicar o letramento científico, em prol de uma aprendizagem que capacite à tomada de decisões pessoais

\footnotetext{
${ }^{4}$ Em inglês, Programme for International Student Assessment, o maior estudo sobre educação do mundo, realizado a cada três anos pela Organização para a Cooperação e Desenvolvimento Econômico - OCDE.
} 
e coletivas, implica na defesa de estratégias metodológicas contextualizadas, por meio da prática de leitura de textos científicos que levem à compreensão das relações ciênciatecnologia-sociedade. Trata-se de um desafio à ressignificação do ensino de ciências, em prol de ações educativas transformadoras que executem o resgate da função social da educação científica (SANTOS, 2007).

As diferenciações dos termos originais, apresentadas por Mamede e Zimmermann (2005) e por Santos (2007), denotam a alfabetização científica como a aprendizagem dos conteúdos e da linguagem científica, muito presentes na preparação para os exames; enquanto o letramento científico aponta para o uso do conhecimento científico e tecnológico no cotidiano dos contextos sócio-históricos em que os indivíduos estão inseridos, focando no domínio da ciência como prática social.

Da mesma forma, a 'literacia' também se refere às habilidades de leitura e escrita. A história de desenvolvimento desse conceito mostra que, apesar de ainda existirem debates em torno de sua definição, a noção aponta para a aquisição de competências em leitura e escrita passíveis de possibilitar aos sujeitos 'competentes' atuarem na cultura em que se inserem, partilhando da vida coletiva em seus contextos socioculturais. O termo é proveniente do inglês literacy, que designa o alfabetismo, mas também envolve um conjunto de domínios vinculados às diversas dimensões das culturas e às capacidades humanas para nelas atuarem. (GABRIEL, 2017; MORAIS; KOLINSKY, 2016; SASSERON; CARVALHO, 2011).

Muito utilizado em Portugal, o conceito ainda é pouco reconhecido no Brasil pelo fato de ainda haver aqui um uso mais intenso do termo "letramento", acompanhado de muitas adjetivações que dão conta dos domínios em que os sujeitos atuam, como por exemplo, letramento científico, letramento financeiro, letramento digital (MORAIS, 2019; MORAIS; KOLINSKY, 2016). De acordo com Gabriel (2017, p. 83, grifos no original), “[...] sem adjetivação, letramento dá conta da inserção do indivíduo no mundo letrado, não o do beletrismo ou das "belas letras", mas em uma sociedade que se organiza a partir de uma gama de gêneros textuais com inúmeras finalidades". Assim, adotar o letramento como perspectiva pedagógica, implica preparar os indivíduos para uma efetiva e competente participação nas dinâmicas sociais e profissionais que envolvem a língua escrita (GABRIEL, 2017).

Para Morais e Kolinsky (2016), o conceito de literacia é mais conveniente para designar o desenvolvimento de habilidades e capacidades necessárias à aquisição da leitura e da escrita, a partir da relação entre sujeito e objeto em perspectiva crítica. Ao abordarem historicamente a noção de literacia científica, os autores lançam luz sobre as controvérsias de sua constituição ao longo da segunda metade do século XX e começo do século XXI, provocando-nos reflexões sobre a relação entre ciência e sociedade. Até o começo do século XXI, a literacia científica significava a compreensão que o público tem da ciência e, aos poucos, com o desenrolar das duas primeiras décadas do século, a capacidade e as habilidades da leitura e da escrita passam a ser entendidas - em seus sentidos mais fundamentais - como constitutivas da ciência e não apenas a partir de uma relação estritamente funcional e instrumental (MORAIS; KOLINSKY, 2016).

A terminologia "literacia científica" é polissêmica e difusa, caracterizada por diversas dimensões de compreensão da ciência ao longo do tempo (CARVALHO, 2009). Contemporaneamente, emerge uma concepção de que é importante promover um nível de literacia científica funcional nas populações, para que possam participar efetivamente das sociedades, produzindo ganhos tanto sociais quanto pessoais, como por exemplo, contribuir para o desenvolvimento econômico do país, apoiar políticas públicas de ciência, influenciar decisões políticas, em âmbito social, bem como melhorar tomadas de decisão e as condições de 
empregabilidade, em âmbito pessoal (MORAIS, 2019; CARVALHO, 2009; VIEIRA, 2007). Tais aprendizagens não ficam restritas ao período da escolarização, pois tratam de um conjunto diversificado de competências, habilidades, capacidades, atitudes e valores acerca dos produtos e processos científicos e sua relação com o saber tecnológico, que se desenvolvem a partir da base escolar, mas progridem continuamente ao longo da vida, de modo que criar atitudes e interesses positivos em relação à ciência, é fundamental (MORAIS, 2019; CARVALHO, 2009; VIEIRA, 2007; CHAGAS, 2000).

Nesse sentido, em uma dimensão mais aprofundada, "Ser proficiente em ciência não é só ser capaz de raciocinar, imaginar, planificar, deliberar, argumentar, é também ser capaz de falar, ler e escrever ciência" (MORAIS; KOLINSKY, 2016, p. 149-150). Trata-se de uma interpenetração quase total da atividade de leitura e escrita e não de um conhecimento memorizado de fatos científicos, ou seja, uma noção de literacia que enfoca a capacidade de desenvolvimento de uma consciência científica crítica sobre nós e sobre o mundo. A partir dessa noção de literacia científica, a intenção primordial da ideia de formação científica que trazemos aqui é a que possa ser pensada como uma dinâmica de manutenção da curiosidade e da vontade de transformação da realidade, por meio do desenvolvimento do senso crítico e da postura reflexiva e criativa em todas as áreas do conhecimento; e não apenas com foco na aprendizagem conceitual ou de saberes relativos ao ensino de ciências naturais.

No entanto, cumpre esclarecer que o que estamos considerando como formação científica difere-se dos conceitos de alfabetização científica e letramento científico, porém os abarcam, ao passo que se conjuga com a literacia científica como um percurso de preparação para ela. Inserido na educação científica mais ampla, o processo de formação científica ocorre no contexto escolar no âmbito da educação científica escolar, conduzindo à literacia científica, por se conjugar com aspectos interrelacionados da educação científica em geral.

A literacia científica é entendida como resultado de uma concepção de formação que considera a autonomia, o protagonismo, a criatividade e a integração dos envolvidos nas rotinas de ensino e aprendizagem, em formatos horizontalizados, participativos e democráticos. É multidimensional e ocorre em todos os níveis de ensino, originando-se de práticas investigativas que não se restringem à relação formal ou conceitual com o conhecimento estabelecido pelas ciências naturais, mas sim uma formação que valoriza, reconhece e incorpora os conceitos de alfabetização científica e letramento científico, ao preparar as pessoas para gestão e uso consciente e reflexivo dos conhecimentos que acessam e/ou produzem.

Essa dinâmica de ensino e aprendizagem visa potencializar, na Educação Básica, o desenvolvimento de habilidades e a ampliação de capacidades para escolhas futuras que permitam encontrar as melhores soluções para os 'problemas' com os quais os estudantes venham a se deparar em qualquer dimensão da vida. Também visa o reconhecimento do valor da ciência para o alcance ou a manutenção do bem-estar, bem como também os riscos de seu uso inadequado. A partir disso, entendemos que "A formação que por fim conduziria à autonomia dos homens precisa levar em conta as condições a que se encontram subordinadas a produção e a reprodução da vida humana em sociedade e na relação com a natureza" (MAAR, 2006, p. 19).

Em Adorno (2006), entendemos que a formação é um processo ocorrido pela via da cultura, somente sendo possível entender seu sentido a partir de sua relação com aquilo que 'ela não é', pois "O conteúdo da experiência formativa não se esgota na relação formal do conhecimento - das ciências naturais, por exemplo - mas implica uma transformação do sujeito no curso do seu contato transformador com o objeto na realidade" (MAAR, 2006, p. 25). Observamos, a partir de Maar (2006), que fazer formação não é a tendência objetiva da 
sociedade dada e que para 'vir a ser', a educação não pode se valer apenas da apropriação de um instrumental técnico e conceitual, mas sim apontar para uma ampla gama de aprendizados que se atenha à dimensão histórica e, mais que isso, possibilite a percepção e o contato com o não-idêntico, o diferenciado. Assim, a educação como formação significa, então, educar 'com' e 'para' a consciência.

Dessa forma, para a viabilidade de uma formação científica que se apresente como uma oportunidade na sociedade contemporânea, são necessárias políticas públicas voltadas à elevação da qualidade da educação em geral, pois, como aponta Morais (2019), a capacidade de ler e escrever é essencial à ampliação do potencial de desenvolvimento do senso crítico dos escolares, como uma preparação para sua participação ativa na sociedade democrática, bem como para identificar domínios de literacia, ou seja, a competência em uma área específica, como, por exemplo, a literacia científica.

\section{A formação científica na Educação Básica como uma oportunidade na sociedade do conhecimento}

O 'fazer ciência' é, ao longo da história do Brasil, considerado uma tarefa da Educação Superior, de modo que, sendo procedimento formativo desvinculado das escolas, é necessário acessar o ensino superior para fazer parte dos ritos especiais reservados a poucos iluminados (DEMO, 2001). Assim, resultado da falta de democratização do acesso ao conhecimento científico, envolvendo questões de variadas ordens, destacando-se as sociais, econômicas e culturais, não é incomum que a grande maioria dos estudantes tenham contato com a estrutura do saber científico somente nas primeiras disciplinas de metodologia ou métodos e técnicas de pesquisa no ensino superior. A escola básica, sobretudo a pública, vivencia essa segregação devido à inúmeras barreiras a ela impostas no cotidiano do trabalho pedagógico, como por exemplo, aspectos estruturais e, muitas vezes, a carência de cultura geral de seu público-alvo (PINZAN; LIMA, 2014).

Entretanto, a educação escolar tem importante papel na trajetória de desenvolvimento e formação do sujeito pesquisador e, nesse sentido, consideramos sua importância para o desenvolvimento de uma ciência voltada à realidade brasileira. A ciência é fundamental para o entendimento da vida e a educação científica é um capital que representa oportunidade na sociedade tecnológica, devido às correlações existentes entre o desenvolvimento científico e tecnológico de um país com a qualidade de vida de seu povo. O investimento em pesquisa científica tem como objetivo principal levar-nos ao conhecimento de tudo que nos rodeia e "Os instrumentos criados pelas novas tecnologias dependem essencialmente de recursos humanos capacitados para acessar informações e transformá-las em conhecimento e inovação" (ROITMAN, 2007, p. 8).

O espírito crítico e reflexivo precisa ser incentivado desde os 'comos' e os 'porquês' da infância, inerentes à curiosidade natural das crianças, sobretudo porque os questionamentos nessa época da vida demarcam o início da atividade consciente acerca do mundo, sendo uma fase considerada ímpar para o estímulo à vontade de aprender, o que proporciona muitas vantagens ao desenvolvimento humano (ROCHA; ALMEIDA; ROCHA, 2019; ROITMAN, 2007). Entendemos, a partir de Rocha, Almeida e Rocha (2019) e Roitman (2007), que o processo formativo deve provocar nos estudantes o desenvolvimento da iniciativa (em detrimento de sua castração), a postura de manutenção do ato de conquistar o conhecimento e que, se os 'porquês' forem estimulados, instigados, ao longo de todo o percurso escolar, tendem a ser gradativamente transpostos/conduzidos às indagações inerentes à investigação científica propriamente dita, de acordo com as peculiaridades de cada ciclo educativo. 
A partir do comportamento das crianças em relação ao mundo, é possível perceber que o conhecimento é um processo em si mesmo, não devendo ser considerado somente uma meta para fins específicos, mas sim parte da experiência do viver e das relações que estabelecemos com os objetos à nossa volta. De um ponto de vista formal, as instituições de Educação Básica ocupam lugar central em nosso percurso educativo, oferecendo-nos as bases do conhecimento, os pilares necessários à inserção produtiva na vida social.

Apesar de estar geralmente associado às universidades, o desenvolvimento do senso crítico como a capacidade de compreender e atuar socialmente, por meio de um conhecimento dialético e não meramente mecanicista e instrumental, é resultado do contínuo trabalho do amadurecimento intelectual dos indivíduos, com vistas à formação para a vida e para o trabalho, por meio, inclusive, das condições necessárias à continuidade dos estudos em níveis subsequentes de ensino. O senso crítico precisa estar relacionado a todo o percurso escolar, gradativamente aprofundando-se o rigor das abordagens dos problemas colocados pelo contato com o real. A pesquisa deve começar na infância e fazer parte da vida escolar, como condição para a cidadania, não fazendo sentido, conforme destaca Demo (2001), dizer que o pesquisador surge somente na pós-graduação em função de suas particularidades formativas. Para Demo (2001, p. 44), "Educação criativa começa na e vive da pesquisa, desde o primeiro dia de vida da criança".

Por meio da abordagem de Demo (2001), em que a pesquisa é princípio científico e educativo, entendemos que se desenvolve no meio educativo formal por intermédio de práticas investigativas entendidas como ações diversificadas inseridas em projetos interdisciplinares ou transdisciplinares, cujo objetivo é a formação humana, estando a transversalidade e a interdisciplinaridade a serviço de uma concepção de conhecimento que toma a realidade como dinâmica e complexa. A educação escolar está inserida em um movimento formativo mais amplo e a curiosidade humana é como um motor para o avanço científico e tecnológico na busca de solucionar problemas e atender a desejos e aspirações. Assim, não se pode idealizar a Educação Superior como espaço exclusivo responsável pela formação científica, sobretudo agora que, a partir de 2021, a criatividade e pensamento crítico serão incorporados como novos domínios à avaliação do PISA (OCDE, 2020).

Com esse entendimento, na próxima seção, apresentamos os resultados de análise documental da política pública atual de educação no Brasil, o Plano Nacional de EducaçãoPNE (2014-2024), anexo à Lei n. 13.005, de 25 de junho de 2014 (BRASIL, 2014), a qual estabelece metas e estratégias para todos os níveis da escolarização no país. Nosso intuito é identificar se a formação científica na Educação Básica está contemplada nesse documento norteador, a fim de contribuir para a aquisição da literacia científica.

\subsection{A formação científica no Plano Nacional de Educação - PNE (2014-2024)}

A partir da técnica da análise de conteúdo de Bardin (1977), a análise categorial foi feita por meio do desmembramento do texto do Plano Nacional de Educação - PNE (2014-2024) em unidades de codificação - palavras ou expressões - que, fragmentadas e novamente reagrupadas no contexto original, permitiram a classificação dos conteúdos das mensagens do documento como mais ou menos distanciados da perspectiva de formação científica ora abordada. Destacamos, como se observa na Tabela 1, as seguintes palavras ou expressões: 'Cidadania'; 'Científica/científico'; 'Crítica/crítico'; 'Crítico-reflexivo'; 'Formação científica'; 'Inovação'; 'Tecnologia'. Para a escolha, consideramos o conceito de formação apresentado e a possibilidade, na política pública analisada, de opções legislativas focadas em oportunidades de formação científica desde os primeiros anos escolares, face à dimensão da importância de 
CT\&I na sociedade atual. Focamos nas competências necessárias à solução de problemas que requerem dos sujeitos sociais tanto atuação cidadã quanto desenvolvimento do senso crítico. Além disso, a escolha teve o intuito de destacar quantas vezes as palavras ou expressões aparecem, bem como os significados a elas atribuídos nos contextos em que estão inseridas.

Tabela 1 - Resultado da busca pelas categorias analíticas estabelecidas para a análise

\begin{tabular}{c|c}
\hline Categorias analíticas & Vezes em que aparece no PNE \\
\hline Cidadania & 3 \\
\hline Científica /científico & $9 / 2$ \\
\hline Crítica/crítico & $0 / 0$ \\
\hline Crítico-reflexivo & 0 \\
\hline Formação científica & 0 \\
\hline Inovação & 6 \\
\hline Tecnologia & 3 \\
\hline
\end{tabular}

Fonte: Elaborada pelos autores (2021), a partir da análise do Plano Nacional de Educação - PNE (2014-2024) (BRASIL, 2014).

A palavra 'cidadania' aparece 3 (três) vezes no PNE (2014-2024), sendo 2 (duas) no Art. 2o- em que constam suas diretrizes, e 1 (uma) na Meta 10 - Estratégia 10.6, relacionada à superação das desigualdades educacionais e à erradicação de todas as formas de discriminação e com foco na formação para o trabalho, com ênfase nos valores morais e éticos em que se fundamenta a sociedade.

As palavras 'crítica/crítico' e as expressões 'crítico-reflexivo' e 'formação científica' não aparecem no documento analisado. Entretanto, o PNE estabelece a Meta 14, para elevação gradual do número de matrículas na pós-graduação stricto sensu, de modo a atingir a titulação anual de 60.000 (sessenta mil) mestres e 25.000 (vinte e cinco mil) doutores. Por meio dessa meta, foram alinhavadas estratégias voltadas à promoção de intercâmbio científico e tecnológico nacional e internacional, elevação do desempenho científico e tecnológico e, consequentemente, da competitividade internacional da pesquisa brasileira, bem como estímulos à inovação, como atividades específicas da Educação Superior. Na Meta 14, estão as passagens em que se destacam as 2 (duas) únicas vezes que a palavra 'científico' aparece no documento. Já 'científica', aparece 9 (nove) vezes, sempre relacionada ao desenvolvimento tecnológico. Diretamente vinculada ao desenvolvimento de C\&T, a 'inovação' aparece no PNE relacionada à Meta 12, vinculada à elevação das taxas de matrícula na educação superior, inclusive na Estratégia 12.14 é destacada a importância da melhoria da qualidade da Educação Básica para o alcance da Meta. Suas estratégias estão, no geral, relacionadas ao mapeamento da demanda e ao fomento da oferta de formação de pessoal de nível superior.

Já a palavra 'tecnologia', aparece 17 (dezessete) vezes no documento, sendo a maioria delas voltada ao seu uso em atividades pedagógicas, assistivas, de educação a distância, ou desenvolvimento de sistemas para acompanhamento de registros e fluxos das instituições do sistema. Apenas em 3 (três) aparições está relacionada aos aspectos formativos que analisamos; mas, da mesma forma que a inovação está voltada a uma maior preparação ao exercício profissional futuro. Apesar de serem expostas no PNE intenções de um processo desenhado para estimular a pesquisa científica e inovativa, não é algo pensado a partir da formação de longo prazo, desde a educação básica, ou seja, considerando a pesquisa como um princípio científico e educativo desde as primeiras etapas da vida escolar, como sugerem Demo (2001) e Roitman (2007). 
Destacamos que a promoção humanística, científica, cultural e tecnológica do país está expressa entre as diretrizes do PNE (2014-2024) (BRASIL, 2014, Art. 2ª, VII); no entanto, formar sujeitos pesquisadores é tarefa de longo prazo, em todos os níveis de escolarização, promovendo maior interesse futuro em C\&I e em Pesquisa e Desenvolvimento - P\&D. A oferta de formação científica escolar é necessária pelo fato de que não somente deve ser considerada a intenção de alavancar os quadros profissionais na área da ciência e tecnologia, mas sim, porque mesmo aqueles que não tendem a seguir carreiras científicas, precisam ser preparados para a compreensão, apropriação e consumo de conhecimentos científicos e tecnológicos, algo hoje imprescindível ao exercício de uma cidadania includente, responsável e participativa, pautada na literacia científica (CARVALHO, 2009; VIEIRA, 2007).

Por meio da análise, confrontamos o PNE (2014-2024) com uma noção de formação científica que entendemos capaz de expressar um conjunto de estratégias com o qual seja possível realizar, junto aos estudantes, um esforço de compreensão do real que, em interação com as experiências cotidianas, seja atrativo, provoque a manutenção do desejo pelo conhecimento e desperte o interesse pela pesquisa. Percebemos que suas metas não contemplam uma perspectiva formativa que se volte ao desenvolvimento do senso crítico dos escolares ao longo da Educação Básica, distanciando-se, assim, da formação científica defendida como um processo de manutenção do olhar questionador acerca do real e da curiosidade natural diante da vida e da educação que, por si só, já deveria ser entendida como um processo criativo (ROCHA; ALMEIDA; ROCHA, 2019; ROITMAN, 2007; DEMO, 2001).

O despertamento e a manutenção do senso crítico envolvem a necessidade de estratégias pedagógicas que, uma vez consubstanciadas em política pública, têm potencial para contribuir para a aquisição da literacia científica, se forem traduzidas em práticas cotidianas do contexto escolar em sua relação com o meio, elevando a qualidade da educação e a percepção crítica do mundo. A falta de metas e estratégias claras à sua realização repercute no desempenho da educação brasileira aferido por indicadores oficiais como IDEB e PISA, que abordaremos a seguir, apontando que ainda há um longo caminho a ser percorrido para que se criem condições de rompimento com os entraves que reservam a literacia a uma minoria da nossa população.

\subsection{O marco situacional da educação no Brasil como um desafio à literacia científica}

Os dados do Anuário Brasileiro da Educação Básica (2019, 2020) demonstram que ainda é preciso muito empenho para o fortalecimento e efetiva implementação do estabelecido no PNE para a educação nacional. O Anuário traz um panorama geral que denota a necessidade de reestabelecer o PNE como uma agenda de Estado (e não de governos), prioritária para a nação, onde o direito à educação ainda é um dos desafios mais urgentes.

Apesar da quase universalização do Ensino Fundamental de nove anos, o sistema ainda reproduz muitas desigualdades e aponta para um cenário complexo e desafiador. Segundo o Indicador de Analfabetismo Funcional - INAF ${ }^{5}$, ainda temos no Brasil 29\% de analfabetos funcionais no conjunto da população de 15 a 64 anos. (ANUÁRIO BRASILEIRO DA EDUCAÇÃO BÁSICA, 2020). Os analfabetos funcionais compõem o nível rudimentar de alfabetização, sendo capazes de lidar com a leitura e escrita de textos curtos, como bilhetes, recados e anúncios, no entanto, podem ter comprometimentos variados em relação aos

\footnotetext{
${ }^{5}$ Consolidado pelo Instituto Paulo Montenegro e apresentado no Anuário Brasileiro de Educação Básica (2020), pelo Movimento Todos pela Educação em parceria com a Editora Moderna.
} 
significados das mensagens (ANUÁRIO BRASILEIRO DA EDUCAÇÃO BÁSICA, 2020; SANTOS, 2007).

A meta estabelecida no PNE (2014-2024) é de garantir que pelo menos $95 \%$ dos estudantes entre 6 e 14 de idade concluam o Ensino Fundamental. Em 2018 e 2019 a taxa líquida ${ }^{6}$ de matrícula foi de $98 \%$, mas a conclusão na idade "certa" é ainda uma meta, pois quase $1 / 4$ dos estudantes termina a etapa com mais de 16 anos de idade, como pode ser observado nas Tabelas 2 e 3 .

Tabela 2 - Jovens de 15 a 17 anos de idade na escola em 2018 e 2019

\begin{tabular}{l|c|c}
\multicolumn{1}{c|}{ Jovens na escola } & $\mathbf{2 0 1 8}$ & $\mathbf{2 0 1 9}$ \\
\hline Jovens de 15 a 17 anos na escola & $91,5 \%$ & $92,5 \%$ \\
\hline Jovens de 15 a 17 anos no Ensino Médio & $68,7 \%$ & $71,1 \%$ \\
\hline Distorção idade/série & $63,6 \%$ & $65,1 \%$
\end{tabular}

Fonte: Elaborada pelos autores (2021), a partir de Anuário Brasileiro da Educação Básica (2019, 2020).

Entre os jovens de 15 a 17 anos de idade, 91,5\% estavam na escola em 2018, e em 2019 o percentual subiu para 92,5\%; entretanto, apenas $68,7 \%$ estavam efetivamente no Ensino Médio (taxa líquida) em 2018 e 71,1\% em 2019. (ANUÁRIO BRASILEIRO DA EDUCAÇÃO BÁSICA, 2019, 2020). Destacamos, na Tabela 2, a distorção idade/série que levou 63,6\% dos jovens a concluírem essa etapa do ensino somente aos 19 anos de idade, em 2018, e 65,1\%, em 2019.

Como podemos observar na Tabela 3, em 2019, da população de 8.826 .901 de jovens de 15 a 17 anos no Brasil, 6.275.056 (71\%) tinham matrícula no Ensino Médio; e 21,2\% estavam ainda matriculados no Ensino Fundamental (em números absolutos, 1.868.664 jovens). Do total, $674.814(7,6 \%)$ estavam fora da escola.

Tabela 3 - Jovens de 15 a 17 anos de idade matriculados no Brasil em 2019

\begin{tabular}{l|c|c} 
População de jovens de $\mathbf{1 5}$ a 17 anos $=\mathbf{8 . 8 2 6 . 9 0 1}$ & $\boldsymbol{\%}$ & Números absolutos \\
\hline Jovens de 15 a 17 anos no Ensino Médio & $71 \%$ & 6.275 .056 \\
\hline Jovens de 15 a 17 anos no Ensino Fundamental & $21,2 \%$ & 1.868 .664 \\
\hline Jovens de 15 a 17 anos fora da escola & $7,6 \%$ & 674.814
\end{tabular}

Fonte: Elaborada pelos autores (2021), a partir de Anuário Brasileiro da Educação Básica (2020)

Os problemas de aprendizagem no Brasil se iniciam ainda na infância, em que os níveis de proficiência em leitura e matemática, em 2016, ficaram abaixo de $50 \%$ na Avaliação Nacional de Alfabetização - ANA: Leitura, 45,3\%; Escrita, 66,1\%; e, Matemática, 45,5\%. (ANUÁRIO BRASILEIRO DA EDUCAÇÃO BÁSICA, 2020). Os últimos resultados gerais disponíveis do Índice de desenvolvimento da educação básica - IDEB ${ }^{7}$, referentes a 2019, foram

\footnotetext{
${ }^{6}$ A taxa líquida é o percentual da população em determinada faixa etária que se encontra matriculada no nível de ensino recomendado a essa faixa etária, sendo, para Creche (0 a 3 anos), Pré-Escola (4 e 5 anos), Ensino Fundamental - EF (6 a 14 anos) e Ensino Médio - EM (15 a 17 anos).

${ }^{7}$ Indicador criado em 2007 que reúne os resultados do fluxo escolar e das médias de desempenho nas avaliações, obtidos por meio do Censo Escolar e das médias de desempenho no Sistema de Avaliação da Educação Básica Saeb. (INEP, 2019a).
} 
5,9 pontos para os Anos Iniciais do Ensino Fundamental; 4,9 para os Anos Finais do Ensino Fundamental; e 4,2 para o Ensino Médio, quando as metas eram: 5,7; 5,2 e 5,0, respectivamente. (BRASIL, 2020a). Tais metas estão definidas no PNE (Meta 7) e visam fomentar a qualidade da Educação Básica, com melhoria do fluxo escolar e da aprendizagem. Para o ano de 2021, as metas são as apresentadas na Tabela 4, de forma comparativa.

Tabela 4 - IDEB - metas e resultados gerais

\begin{tabular}{l|c|c|c|c|c|c|c}
\multicolumn{1}{c|}{ IDEB } & \multicolumn{2}{c|}{$\mathbf{2 0 1 5}$} & \multicolumn{2}{c|}{$\mathbf{2 0 1 7}$} & \multicolumn{2}{c|}{$\mathbf{2 0 1 9}$} & $\mathbf{2 0 2 1}$ \\
\hline & Metas & Resultados & Metas & Resultados & Metas & Resultados & Metas \\
\hline EF anos iniciais & 5,2 & 5,5 & 5,5 & 5,8 & 5,7 & 5,9 & 6,0 \\
\hline EF anos finais & 4,7 & 4,5 & 5,0 & 4,7 & 5,2 & 4,9 & 5,5 \\
\hline EM & 4,3 & 3,7 & 4,7 & 3,8 & 5,0 & 4,2 & 5,2
\end{tabular}

Fonte: Elaborada pelos autores (2021), a partir de PNE (2014-2024) (BRASIL, 2014) e BRASIL (2020a).

Os dados observados do IDEB, ao longo da série histórica, de um modo geral, apontam a fragilidade do nível de proficiência dos estudantes a partir do Ensino fundamental II, que se aprofunda no Ensino Médio, sobretudo em matemática, denotando a fragilidade das políticas de educação no Brasil que põe em xeque o futuro de milhões de jovens, bem como dificulta a realização de um país mais justo, equânime e desenvolvido. Conforme aponta o Relatório do $3^{\circ}$ Ciclo de monitoramento das metas do $\mathrm{PNE}^{8}$ (BRASIL, 2020b), os resultados alcançados estão muito aquém do planejado, o que implica em urgência no replanejamento e projeção de novas estratégias e metas. Para Helene (2013), o Ensino Fundamental somente está universalizado em seu ingresso, pois o percurso escolar é de exclusão, culminando com a grave crise do Ensino Médio, instaurando-se um ciclo vicioso difícil de se resolver. O autor questiona: "Afinal, como melhorar e aumentar o ensino médio, por exemplo, sem aumentar e melhorar o ensino fundamental que o antecede ou sem formar professores no nível superior, este último dependente dos concluintes do próprio ensino médio?” (HELENE, 2013, p. 136).

No cenário internacional, o PISA revelou, na edição 2018, que o Brasil possui baixo desempenho em leitura, matemática e ciências. A comparação foi feita com outros 78 países que participaram do exame que avalia a capacidade de jovens de 15 anos para o uso de conhecimentos e habilidades de leitura, matemática e ciências para o enfrentamento dos desafios da vida real. Em 2018, 79 países e 600 mil estudantes participaram do teste, que ocorre desde 2000 (BRASIL, 2019b). Na Tabela 5, apresentamos as posições que o país ocupou entre os países participantes da avaliação.

Tabela 5 - Posição do Brasil no PISA em 2018 entre os 79 países participantes

\begin{tabular}{c|c|c|c} 
& Leitura & Matemática & Ciências \\
\hline Média OCDE & 487 & 489 & 489 \\
\hline Média Brasil & $\mathbf{4 1 3}$ & $\mathbf{3 8 4}$ & $\mathbf{4 0 4}$ \\
\hline Margem de erro & 2 & 2 & 2 \\
\hline Faixa no ranking* & $55-59$ & $69-72$ & $64-67$
\end{tabular}

Fonte: Elaborada pelos autores (2021), a partir de BRASIL (2019b).

*Considerando-se a margem de erro.

\footnotetext{
${ }^{8}$ Em determinação à Lei no 13.005 , de 25 de junho de 2014, é atribuição do Instituto Nacional de Estudos e Pesquisas Educacionais Anísio Teixeira - INEP - publicar, a cada biênio, relatórios sobre a evolução do cumprimento das metas estabelecidas no PNE. (BRASIL, 2020b). O primeiro foi publicado em 2016 e o segundo em 2018. Em todos é possível observar o não atingimento das metas estabelecidas.
} 
Os dados das colocações destacadas na Tabela 5 apontam para 68,1\% dos estudantes brasileiros avaliados, com 15 anos de idade, que não possuem nível básico mínimo em matemática, essencial para o exercício da cidadania. Em ciências, esse percentual é de $55 \%$ e, em leitura, 50\%, seguindo estagnados desde 2009 (BRASIL, 2019b). A Meta 7 do PNE prevê o fomento da qualidade da educação, e a Estratégia 11 dessa Meta está diretamente relacionada ao PISA, tomado como instrumento externo de referência. O PISA é reconhecido internacionalmente e as projeções foram de 438 e 455 pontos para os anos de 2015 e 2018 , respectivamente, e para o ano de $2021^{9}$ estão estimados 473 pontos nas três áreas avaliadas (BRASIL, 2014).

Entre os países da América do Sul participantes do PISA em 2018, o Brasil ocupou o último lugar em matemática, empatado estatisticamente com a Argentina, com 384 e 379 pontos, respectivamente, ficando atrás de Uruguai (418), Chile (417), Peru (400) e Colômbia (391). Em ciências, também ocupou o último lugar, com 404 pontos, empatado com os vizinhos Argentina e Peru; os melhores classificados foram Chile (444), Uruguai (426) e Colômbia (413). Já em leitura, ficou em segundo pior lugar do ranking sul-americano, com 413 pontos, ao lado da Colômbia (412). Por último, aparecem Argentina (402) e Peru (401) (BRASIL, 2019b).

As desigualdades em âmbito internacional são um reflexo das assimetrias internas da nação brasileira. Uma análise comparativa das dependências administrativas feita a partir dos dados disponibilizados pelo Instituto Nacional de Estudos e Pesquisas Educacionais Anísio Teixeira - INEP (BRASIL, 2019a) revela que as escolas particulares e federais acompanham a média dos países da OCDE, ficando as estaduais e municipais com desempenho abaixo do esperado. Por outro lado, é significativa também a desigualdade entre as regiões, pois a Norte e a Nordeste se apresentam com os piores números nas três áreas avaliadas.

Nesse contexto, percebemos que a análise dos dados nacionais e internacionais exigem reflexão acerca das condições educacionais no Brasil, com ênfase para as regiões, pelo fato de que as desigualdades socioculturais e as desigualdades da linguagem interagem entre si, já que a linguagem pode ser considerada ao mesmo tempo como um produto e um instrumento das desigualdades socioculturais que caracterizam as sociedades humanas (MORAIS, 2019). Os indicadores denotam desigualdades em leitura, escrita e conhecimento básico em ciências que se reportam às dificuldades reais para que os estudantes avancem em seus estudos, que aproveitem melhores oportunidades na vida e no mercado de trabalho e participem da sociedade de forma cidadã. São milhares de jovens com limitações ou mesmo incapacidades para leitura, compreensão e interpretação de textos; resolução de cálculos e compreensão de questões científicas cotidianas simples, o que revela uma inadequada aquisição da literacia por grande parcela da população. Quando os jovens não desenvolvem habilidades na escola, suas condições de vida são afetadas, o que prejudica o aprofundamento do sentido democrático para a vida coletiva (MORAIS, 2019).

Com esse quadro, garantir a literacia científica para todos, é um grande desafio que se refere a investimentos financeiros, mas também a questões culturais relativas à trajetória do Brasil como nação, suas heranças históricas e mecanismos estruturais de perpetuação da pobreza e das desigualdades sociais. Em matéria de educação, o PNE (2014-2024) precisa ser

\footnotetext{
${ }^{9}$ De acordo com o website da OECD na internet (https://www.oecd.org/pisa/), os países membros associados decidiram, em função da pandemia de Covid-19, adiar o exame que ocorreria em 2021 para 2022 e o de 2024 deverá ser realizado em 2025. Acesso em: 05 maio 2021.
} 
retomado de modo a resgatar o potencial da educação brasileira para a construção de uma nação próspera, amparada por um novo ciclo de desenvolvimento que parta do potencial científico e tecnológico já instalado. Nesse sentido, os avanços percebidos e os resultados positivos na universalização do Ensino fundamental precisam ser estendidos ao Ensino Médio, ofertados a todos de forma equitativa, com a qualidade necessária à elevação de seu desempenho.

Para tanto, são necessárias adequações nas políticas voltadas às questões estruturais, bem como aos recursos humanos e materiais. Em relação aos recursos humanos, destacamos que toda a equipe escolar possui relevância no processo educativo. No entanto, a formação continuada e a valorização dos professores precisam ser consideradas como estratégias governamentais fundamentais na tarefa de despertar o senso crítico e de manutenção do 'espírito questionador' inerente às crianças. Elevar a qualidade da Educação Básica é tarefa de longo prazo, passando, entre outros fatores, pela melhoria da qualidade da formação de professores, a partir de uma compreensão de que docência e pesquisa são indissociáveis (BRITO, 2013; DEMO, 2001). Os docentes precisam ser valorizados e qualificados por meio da pesquisa, com o intuito de desenvolver e aprimorar continuamente suas capacidades de reflexão crítica e do uso do método científico e, consequentemente, sua prática, despertando o respeito e o interesse da sociedade pela profissão (BRITO, 2013).

De acordo com Vieira $(2007,105)$, “a literacia científica está ligada à forma como os adultos se posicionam face à ciência". Isso ganha proporção quando consideramos a importância dos professores na condução das estratégias de formação científica, bem como ao impactar no modo como os estudantes aprendem e como isso pode condicionar suas atitudes futuras. Os indicadores denotam que são poucos os estudantes que finalizam o ciclo escolar básico "[...] com um conhecimento de ciência tal que permita afirmar-se que são cientificamente literatos" (VIEIRA, 2007, p.105). Mas, contraditoriamente, é na escola que os estudantes são introduzidos no domínio da ciência e nas questões que a envolvem, assim sendo, o objetivo desse ensino deve ser "[...] formar uma população que considere a ciência interessante e importante, que consiga aplicar conhecimentos da ciência no seu quotidiano, e que consiga participar em debates relacionados com questões/problemas científicos" (VIEIRA, 2007, p. 105).

Melhorar a qualidade da educação em geral, e da educação científica em particular, requer habilidades mais amplas de leitura e escrita para todos, em todos os níveis, promovendo a literacia nos seus variados domínios ${ }^{10}$. Morais e Kolinsky (2016) defendem a leitura e a escrita de artigos científicos, iniciando-se já no ensino secundário, sustentada por práticas anteriores de contato com a educação para a literacia científica. Essa questão nos leva ao entendimento de que a preparação para esse domínio da literacia significa também aprender a consumir ciência, inclusive, as informações científicas que circulam de forma acessível nos distintos meios disponíveis atualmente, "ao alcance da mão", diferenciando o que é confiável do que não é.

Em muitas situações, mediadas pela capacidade de ler e escrever, vários domínios de literacia se conjugam e se interpenetram, porém, "Não tem o mesmo efeito ler artigos científicos ou artigos de divulgação científica. [...] o gênero do texto tem influência na formação científica: a leitura de artigos científicos ajuda a integrar modos de pensar que são os da ciência" (MORAIS; KOLINSKY, 2016, p. 153). Contudo, a ampliação da capacidade de consumir tanto ciência quanto informações científicas tem relação com a popularização, valorização e percepção pública de C\&T, compondo o estado de literacia científica alcançado pela população.

10 Relacionados às competências em distintas áreas como literária, científica, midiática, digital, de saúde, financeira, sanitária, informacional, entre outras (MORAIS, 2019; MORAIS; KOLINSKY, 2016). 
De forma ilustrativa dessa relação, abordaremos no tópico 4 os resultados da quinta edição da pesquisa 'Percepção pública da C\&T no Brasil - 2019'11 (CGEE, 2019).

\section{A importância da educação para a popularização científica e a percepção pública da C\&T no Brasil}

Para o proposto neste trabalho, consideramos a literacia científica sobremaneira importante para a compreensão do conteúdo sociopolítico da ciência e da tecnologia, visto que há uma permanente seleção entre as opções científicas e tecnológicas, a depender das necessidades de cada contexto, da conjuntura de cada sociedade. A ciência e a tecnologia requerem aceitabilidade social, legitimação e, como outras atividades humanas, também necessitam de uma base de legitimidade, justamente porque há uma dimensão cultural significativa que precisa ser considerada nos debates em torno delas (TRIGUEIRO, 2009).

A legitimação compreende todo um processo de interações entre indivíduos e instituições, buscando a formação de consensos em torno de determinadas questões, e sua natureza é dinâmica, processual e combina a atuação das normas jurídicas e sociais, mas, também, os 'fatores contingentes', ou seja, o imprevisível (TRIGUEIRO, 2009). Em suma, a pesquisa científica é realizada por cientistas, mas o modo como é realizada, na prática, traz à evidência elementos constitutivos de sua atividade que não se limitam a uma estrita racionalidade técnica instrumental, devido a ser condicionada por uma ampla gama de fatores que têm a ver com sua legitimação e legitimidade (TRIGUEIRO, 2009).

A pesquisa 'Percepção Pública da C\&T no Brasil - 2019'12 teve como objetivo conhecer a visão, o interesse e o grau de informação da população em relação à C\&T no País. Aponta o CGEE (2019) que 62\% dos respondentes estão interessados ou muito interessados em algum assunto relacionado à C\&T. Entre os dados, chamou-nos a atenção uma visão positiva sobre C\&T por parte de $92 \%$ dos entrevistados em 2019, reafirmando um olhar sobre o tema que se manteve positivo de forma constante ao longo do tempo (CGEE, 2019). Entretanto, é constante o descompasso no interesse entre grupos sociais diferentes, considerando-se de alta e baixa escolaridade e de baixa e alta renda: "O percentual de brasileiros que declaram ter nenhum interesse em C\&T caiu quase para zero entre pessoas com nível de ensino superior. Praticamente, a totalidade dos "nada interessados", 15\%, encontra-se entre pessoas com escolaridade inferior à do ensino superior (CGEE, 2019, p. 14). Um dado interessante é que entre entrevistados de alta escolaridade, a confiança nos cientistas alcançou o primeiro lugar nas preferências.

Por outro lado, os indicadores demonstram escassos acesso e apropriação do conhecimento científico por parte dos brasileiros. Apesar da relativa facilidade de acesso às mídias, não há por parte do público hábitos de busca de informação acerca da C\&T: 70\% declaram acessar a internet todos os dias e outros $11 \%$ de forma mais esporádica, toda semana ou mês, contra 19\% que declararam não ter acesso. Entretanto, 93\%, raramente ou nunca, buscam informação sobre C\&T nos meios de divulgação. Tais dados são reveladores da carência da literacia científica, em um contexto de acesso amplo e facilitado, a conteúdos e informações de interesse geral.

\footnotetext{
${ }^{11}$ As pesquisas de percepção da CT\&I têm se tornado uma prática relevante no mundo. No Brasil, a primeira foi realizada em 1987, tendo sequência em 2006, 2010, 2015 e em 2019 (CGEE, 2019).

${ }^{12}$ A pesquisa contou com 2.200 participantes, em idade superior a 16 anos, e cotas por gênero, idade, escolaridade, renda e local de moradia em todas as regiões do país.
} 
Nesse passo, em 2019, 90\% dos brasileiros não se lembraram ou não sabiam apontar um cientista do País; e $88 \%$ não se lembravam ou não sabiam indicar uma instituição do setor. Nem universidades foram muito citadas nas respostas, apesar de serem os principais centros de produção de conhecimento científico. Apesar disso, revelou-se constante o apoio dos brasileiros aos investimentos em C\&T: em 2019, 66\% se declaram favoráveis a aumentos e 24\%, a manter os investimentos em pesquisa, contra $6 \%$ que acreditam que devam ser diminuídos. Um dado que pode ser relacionado a este, refere-se ao número de pessoas que consideram o Brasil "atrasado" no campo das pesquisas científicas e tecnológicas: um aumento expressivo de 2010 para 2019: 28\% (2010), 43\% (2015) e 54\% (CGEE, 2019).

A pesquisa de percepção revelou ainda que as atitudes dos brasileiros sobre aspectos específicos da C\&T mudaram bastante nos últimos anos, mas se mantendo positivas, pois os cidadãos tendem a concordar sobre a utilidade e importância da pesquisa e da tecnologia. Os brasileiros respeitam e valorizam a C\&T, e esperam maior investimento, porque entendem que no fazer científico está a chave para o futuro; mas têm pouco acesso e baixo consumo de informações sobre o assunto (CGEE, 2019). A razão principal para isso reside na ausência de uma educação científica abrangente e de qualidade no Ensino Fundamental e Médio do país. Nesse sentido, a sociedade, a comunidade científica e o governo devem unir forças para difundir a C\&T no país, aponta o CGEE (2019). Nesta perspectiva, afirma Araújo (2016, p. 15) que “[...] é cada vez mais urgente que a sociedade possa participar ativamente e ser informada sobre os rumos do desenvolvimento em Ciência, Tecnologia e Inovação (CT\&I)." Constatação que, para a autora, passa pelo reconhecimento das ações voltadas à popularização da ciência e possa empoderar os cidadãos para o pleno exercício da democracia.

\begin{abstract}
Investir no conhecimento científico contribuirá para que os seus resultados estejam ao alcance de todos. Além disso, é fundamental para que a sociedade possa compreender a importância da ciência no cotidiano. Ela também representa o primeiro degrau da formação de recursos humanos para as atividades de pesquisa científica e tecnológica (ROITMAN, 2007, p. 8).
\end{abstract}

Face ao exposto, reiteramos a importância do desenvolvimento, ao longo da vida, das capacidades relacionadas à aquisição da literacia científica. Esse fator é fruto de um processo de formação científica escolar através de estratégias pedagógicas consistentes de investigação científica e desenvolvimento do senso crítico em todas as áreas do saber e em todos os níveis de escolarização. A educação científica não é exclusiva da escola, porém, é nela que a literacia científica encontra as possibilidades do saber sistematizado, com potencial para elevação da qualidade da educação e da valorização da ciência pela sociedade.

\begin{abstract}
A liberdade de pensamento e de expressão e o pensamento crítico são as duas condições que toda sociedade, todo governo, todo sistema educativo, deve garantir e estimular. Sem liberdade e sem espírito crítico não há renovação nem aprofundamento da literacia. E quando liberdade e espírito crítico são ameaçados, para defendê-los é necessário que os letrados e a literacia se mantenham firmes, inalteráveis e irreverentes, custe o que custar, face à opressão e à repressão (MORAIS; KOLINSKY, 2016, p. 147).
\end{abstract}

Os estudantes precisam acessar, de forma equânime, oportunidades que lhes possibilitem a preparação para carreiras científicas em todas as áreas do conhecimento, o que implica também pensar nas condições para o alcance e satisfação desse interesse, 
principalmente, para os jovens. Nesse sentido, o país precisa de uma revisão urgente do seu Plano Nacional de Educação - PNE (2014-2024). Ao considerarmos que os resultados dos indicadores revelam o não atingimento das metas estabelecidas, entendemos que o quadro se agrava com as ingerências nas estratégias das políticas institucionais adotadas no âmbito educacional em todo território brasileiro no contexto da pandemia de Covid-19.

No que concerne aos indicadores aqui analisados, é relevante pontuar que o PISA 2021 está adiado para o ano de 2022, e o PISA de 2024 para 2025, em função das dificuldades enfrentadas em virtude da pandemia de Covid-19. Relevante, ainda considerar, que a partir de informações obtidas no sítio do Governo Brasileiro (BRASIL, [s.a], [s.p]), o PISA 2022 já se encontra em preparação e o domínio principal da edição será 'matemática'. As dificuldades encontradas pelos escolares, suas famílias e pelos sistemas de ensino, sobretudo públicos, para enfrentar a crise sanitária e socioeconômica que afeta o país, direcionam as perspectivas do Brasil a um declínio nas posições nos resultados futuros. Esforços precisam ser empenhados por todas as áreas do conhecimento, em prol da reformulação das políticas públicas no Brasil, entre elas, a de educação, com vistas ao desenvolvimento de capacidades humanas que elevem as expectativas para todos, sobretudo em relação à literacia científica.

\section{Considerações finais}

Neste trabalho, entendemos a formação científica em todos os níveis de ensino como uma estratégia para a educação com e para a consciência científica, espaço ímpar para a realização da interdisciplinaridade e transversalidade, que pode, em função de seus conteúdos, potencializar o desenvolvimento de competências no domínio da literacia científica, fundamental à atuação democrática, crítica e reflexiva na sociedade do conhecimento.

A análise do Plano Nacional de Educação - PNE (2014-2024) apontou que, apesar da ênfase em ciência e tecnologia estar relacionada à Educação Superior, a promoção humanística, científica, cultural e tecnológica do país faz parte das diretrizes do PNE, porém a formação científica não é pensada a longo prazo. É preciso preparar os estudantes durante toda a vida escolar, promovendo o desenvolvimento de habilidades e competências tanto para as carreiras científicas quanto para a compreensão, apropriação e consumo de conhecimentos científicos e tecnológicos, para o exercício de uma cidadania includente, responsável e participativa, pautada na literacia científica.

Os dados indicadores da Educação Básica brasileira apontam que há ainda um longo caminho pela frente para que o país tenha condições mais favoráveis para romper com situações de desigualdade na educação, que reservam a literacia, em geral, bem como a literacia científica, em particular, a uma minoria da nossa população. Por outro lado, os dados da pesquisa 'Percepção Pública da C\&T no Brasil - 2019' revelam que, quanto mais escolarizados, mais os indivíduos tendem a valorizar as ações de ciência e tecnologia, tendo em vista que as ações nessa área requerem aceitabilidade social, legitimação e, como outras atividades humanas, necessariamente, uma base de legitimidade.

O caráter interdisciplinar da análise nos possibilitou inferir acerca da importância do investimento em ações de formação científica na Educação Básica, como parte da política de educação nacional, e dimensão fundamental do desenvolvimento da literacia científica, pois a formação científica é um processo dinâmico de capacitação dos sujeitos para a vida coletiva na sociedade do conhecimento. Nesse sentido, verificamos a necessidade de mudanças nos direcionamentos em matéria de educação, no sentido de ofertar de forma equitativa e democrática a formação científica a todos os escolares, tendo-se em vista que a complexidade 
das dinâmicas sociais, políticas e econômicas nos desafiam a pensar o Brasil pós-pandemia e a criar soluções para sair da crise. As saídas possíveis implicam em dinâmica política com capacidade de dimensionar o peso de uma agenda efetiva e robusta, que permita maior alcance da literacia científica para que o país possa se posicionar melhor no futuro, a partir de estratégias de desenvolvimento e popularização de CT\&I que incorporem autonomia, criatividade e pensamento crítico como dimensões essenciais.

\section{Referências}

ADORNO, Theodor W. Educação e emancipação. Tradução de Wolfgang Leo Maar. 4. ed. São Paulo: Paz e terra, 2006.

ARAÚJO, F. S. B. Popularização de Ciência, Tecnologia e Inovação (CT\&I) na Universidade Federal do Recôncavo da Bahia (UFRB): subsídios para política institucional. 2016. 138 f. Dissertação (Mestrado em Gestão de Políticas Públicas e Segurança Social) - Universidade Federal do Recôncavo da Bahia, Cruz das Almas, 2016.

ANUÁRIO BRASILEIRO DA EDUCAÇÃO BÁSICA 2019. Todos pela educação/Editora Moderna. 2019. Disponível em:

https://www.todospelaeducacao.org.br/_uploads/_posts/302.pdf. Acesso em: 02 set. 2020.

ANUÁRIO BRASILEIRO DA EDUCAÇÃO BÁSICA 2020. Todos pela educação/Editora Moderna. 2020. Disponível em: https://todospelaeducacao.org.br/wordpress/wpcontent/uploads/securepdfs/2020/10/Anuario-Brasileiro-Educacao-Basica-2020-weboutubro.pdf. Acesso em: 15 jan. 2021.

BARDIN, L. Análise de conteúdo. Lisboa: Edições 70 Ltda., 1977.

BRASIL. Lei n. 13.005, de 25 de junho de 2014. Aprova o Plano Nacional de Educação PNE e dá outras providências. Disponível em:

http://www.planalto.gov.br/ccivil_03/_ato2011-2014/2014/lei/113005.htm. Acesso em: 17 out. 2017.

BRASIL. Instituto Nacional de Estudos e Pesquisas Educacionais Anísio Teixeira (Inep).

IDEB - Resultados e Metas. Brasília, 2020a. Disponível em:

http://ideb.inep.gov.br/resultado/. Acesso em: 15 jan. 2021.

BRASIL. Instituto Nacional de Estudos e Pesquisas Educacionais Anísio Teixeira (Inep).

Metas IDEB: o que são as metas de qualidade educacional. Brasília, MEC, 2019a. Disponível em: http://portal.inep.gov.br/educacao-basica/ideb/metas. Acesso em: 06 jun. 2020.

BRASIL. Instituto Nacional de Estudos e Pesquisas Educacionais Anísio Teixeira (Inep). Pisa 2018 revela baixo desempenho escolar em leitura, matemática e ciências no Brasil. Brasília, MEC, 2019b. Disponível em: http://portal.inep.gov.br/artigo//asset_publisher/B4AQV9zFY7Bv/content/pisa-2018-revela-baixo-desempenho-escolar-emleitura-matematica-e-ciencias-no-brasil/21206. Acesso em: $18 \mathrm{dez} .2020$.

BRASIL. Instituto Nacional de Estudos e Pesquisas Educacionais Anísio Teixeira (Inep). Programa Internacional de avaliação de estudantes (Pisa). Disponível em: 
https://www.gov.br/inep/pt-br/areas-de-atuacao/avaliacao-e-exames-educacionais/pisa. Acesso em: 07 maio 2021.

BRASIL. Instituto Nacional de Estudos e Pesquisas Educacionais Anísio Teixeira (Inep). Relatório do $3^{\circ}$ Ciclo de monitoramento das metas do Plano Nacional de Educação 2020: Sumário executivo. Brasília, 2020b. Disponível em: http://portal.inep.gov.br/informacao-da-publicacao//asset_publisher/6JYIsGMAMkW1/document/id/6974122. Acesso em: 16 fev. 2021.

BRITO, T. F. O que é que a Finlândia tem? Notas sobre um sistema educacional de alto desempenho. Textos para discussão, Brasília, n. 129, 2013. Disponível em: https://www12.senado.leg.br/publicacoes/estudos-legislativos/tipos-de-estudos/textos-paradiscussao/td-129-2018o-que-e-que-a-finlandia-tem-2019-notas-sobre-um-sistemaeducacional-de-altodesempenho\#: :text=Desde\%20a\%20divulga\%C3\%A7\%C3\%A3o\%20dos\%20primeiros,men or\%20desigualdade\%20entre\%20as\%20escolas. Acesso em: 23 abr. 2021.

CARVALHO, G. S. Literacia científica: conceitos e dimensões. In: AZEVEDO, F.; SARDINHA, M.G. (coord.). Modelos e práticas em literacia. Lisboa: Lidel, 2009. p.179194.

CGEE. CENTRO DE GESTÃO E ESTUDOS ESTRATÉGICOS. Percepção pública da C\&T no Brasil - 2019. Resumo executivo. Brasília, DF: Centro de Gestão e Estudos Estratégicos, 2019.

CHAGAS, I. Literacia científica. O grande desafio para a escola. In: ACTAS DO $1^{\circ}$ ENCONTRO NACIONAL DE INVESTIGAÇÃO E FORMAÇÃO, GLOBALIZAÇÃO E DESENVOLVIMENTO PROFISSIONAL DO PROFESSOR. 1., 2000, Lisboa. Anais [...]. Lisboa: Escola Superior de Educação de Lisboa, 2000. Disponível em: http://www.educ.fc.ul.pt/docentes/ichagas/index.html/LiteraciaCientifica.pdf. Acesso em: 15 jan. 2021.

CHASSOT, A. Alfabetização científica: uma possibilidade para a inclusão social. Revista brasileira de educação, n. 22, p. 89-100, jan./abr. 2003. Disponível em: https://www.scielo.br/pdf/rbedu/n22/n22a09.pdf. Acesso em: 27 jan. 2020.

DEMO, Pedro. Pesquisa: princípio científico e educativo. 8. ed. São Paulo: Cortez, 2001.

GABRIEL, R. Letramento, alfabetização e literacia: um olhar a partir da ciência da leitura. Revista Prâksis, ano 14, v. 2, jul./dez. 2017. Disponível em: https://periodicos.feevale.br/seer/index.php/revistapraksis/article/view/1277/1890. Acesso em: 15 jan. 2021.

HELENE, Otaviano. Um diagnóstico da educação brasileira e de seu financiamento. Campinas, SP: Autores associados, 2013. (Coleção educação contemporânea).

MAAR, W. L. À guisa de introdução: Adorno e a experiência formativa. In: ADORNO, Theodor W. Educação e emancipação. Tradução de Wolfgang Leo Maar. 4. ed. São Paulo: Paz e terra, 2006. p. 11-28. 
MAMEDE, M.; ZIMMERMANN, E. Letramento científico e CTS na formação de professores para o ensino de ciências. Enseñanza de las Ciencias, p. 1-4, 2005, Número Extra referente ao VII Congresso Internacional. Disponível em:

https://ddd.uab.cat/pub/edlc/edlc_a2005nEXTRA/edlc_a2005nEXTRAp320letcie.pdf. Acesso em: 23 jul. 2018.

MORAIS, J. O que faz a diferença entre a linguagem rica e a linguagem pobre? Signo, Santa Cruz do Sul, v. 44, n. 81, p. 02-21, set./dez. 2019. Disponível em:

https://online.unisc.br/seer/index.php/signo/article/view/14574/pdf_1. Acesso em: 15 jan. 2021.

MORAIS, J.; KOLINSKY, R. Literacia científica: leitura e produção de textos científicos. Educar em Revista, Curitiba, n. 62, p. 143-162, out./dez. 2016. Disponível em:

https://www.scielo.br/pdf/er/n62/1984-0411-er-62-00143.pdf. Acesso em: 15 de jan. 2021.

MURI, A. F. Letramento Científico no Brasil e no Japão a partir dos resultados do PISA. 2017. 238 f. Tese (Doutorado em Educação) - Departamento de Educação do Centro de Teologia e Ciências Humanas, Pontifícia Universidade Católica do Rio de Janeiro, Rio de Janeiro, 2017.

OCDE. ORGANIZAÇÃO PARA A COOPERAÇÃO E DESENVOLVIMENTO ECONÔMICO. CENTRO DE PESQUISA E INOVAÇÃO EM EDUCAÇÃO.

Desenvolvimento da criatividade e do pensamento crítico dos estudantes: o que significa na escola. [coordenação geral Instituto Ayrton Senna; tradução Carbajal Traduções]. São Paulo: Fundação Santillana, 2020.

PINZAN, M. E.; LIMA, A. P. Iniciação científica na educação básica: uma possibilidade de democratização da produção científica. In: IX EPCT - ENCONTRO DE PRODUÇÃO CIENTÍFICA E TECNOLÓGICA (TECNOLOGIAS E UNIVERSIDADE), 9., 2014, Campo Mourão. Anais [...]. Campo Mourão: UNESPAR, 2014. Disponível em:http://www.fecilcam.br/nupem/anais_ix_epct/PDF/TRABALHOS-COMPLETO/AnaisCH/10.pdf. Acesso em: 13 dez. 2019.

ROCHA, S. M. da; ALMEIDA, C. R. de; ROCHA, R. R. de C. Dos "porquês" da infância aos "porquês" da pesquisa: reflexões sobre a importância da educação escolar para a formação de pesquisadores. In: PINTO, R.; GLASENAPP, R. (coord.). Propostas para uma nova nação: o futuro do Brasil em perspectivas. Belo Horizonte: Editora D’Plácido, 2019. p. 279-293.

ROITMAN, I. Educação científica: quanto mais cedo melhor. Brasília: RITLA, 2007.

SANTOS, W. L. P dos. Educação científica na perspectiva de letramento como prática social: funções, princípios e desafios. Revista Brasileira de Educação, v. 12, n. 36, p. 474-550, set./dez. 2007. Disponível em: https://www.scielo.br/pdf/rbedu/v12n36/a07v1236.pdf. Acesso em: maio 2020.

SASSERON, L. H.; CARVALHO, A. M. P. de. Alfabetização científica: uma revisão bibliográfica. Investigações em Ensino de Ciências, v. 16, n. 1, p. 59-77, 2011. Disponível 
em: https://www.if.ufrgs.br/cref/ojs/index.php/ienci/article/view/246. Acesso em: 03 set. 2019.

TRIGUEIRO, M. G. S. Sociologia da Tecnologia: bioprospecção e legitimação. São Paulo: Centauro, 2009.

VIEIRA, N. Literacia Científica e Educação de Ciência: dois objectivos para a mesma aula. Revista Lusófona de Educação, n. 10, p. 97-108, 2007. Disponível em: https://revistas.ulusofona.pt/index.php/rleducacao/article/view/636. Acesso em: 15 jan. 2021.

Recebido em fevereiro de 2021.

Aprovado em maio de 2021. 